\title{
STUDY ON THE SYNTHESIS OF MESOPOROUS CERIA IN THE PRESENCE OF GLUCOSE AND ACRYLAMIDE
}

\author{
YUAN LI ${ }^{1,2}$, LAITAO LUO ${ }^{I^{*}}$ \\ ${ }^{1}$ Institute of Applied Chemistry, Nanchang University, Nanchang 330031, China \\ ${ }_{2}^{2}$ School of Chemistry and Chemical Engineering, Jiangxi Normal University, Nanchang 330022, China \\ (Received: August 20, 2008 - Accepted: January 21, 2009)
}

\begin{abstract}
Mesoporous ceria with high specific surface area have been prepared using ceric ammonium nitrate and non-surfactants organic compounds glucose, acrylamide via hydrothermal method. The influence of the main synthesis variables have been studied, including cerium ion valence, composition of raw materials, hydrothermal temperature and time. XRD, TEM, TG and nitrogen adsorption techniques have been used to characterize the samples. Results indicate that cerium ion valence has the most important effect on surface area of mesoporous ceria. Cerium ion valence changing from +3 to +4 causes higher surface area of samples. Moreover the coexistence of glucose and acrylamide in the synthesis is essential to obtain samples with high surface areas, whereas surface areas of samples are lower in the absence of glucose or acrylamide. TEM shows that the mesoporous ceria are composed of three-dimensional disordered primary nanoparticles. The average size of primary particles and mesopores are both a few nanometers.
\end{abstract}

Key words: mesoporous ceria; hydrothermal synthesis; glucose; acrylamide

\section{INTRODUCTION}

Cerium dioxide is one of the most studied materials for use in redox catalytic reactions as a catalyst support or assist agent. Its unique crystal structure, high oxygen storage capacity (OSC) and strong redox performance are the main properties. However its low surface area would limit metal dispersion on it. Preparation of ceria with mesopores will efficiently enlarge surface area.

Like other mesoporous inorganic oxides such as $\mathrm{SiO}_{2}, \mathrm{Al}_{2} \mathrm{O}_{3}, \mathrm{TiO}_{2}, \mathrm{ZrO}_{2}$, mesoporous ceria have been prepared via surfactant-assisted routes, namely, adding in the process various types of surfactants as templates to assemble and organize inorganic frameworks by electrostatic, hydrogen-bonding, covalentbonding, and van der Waals interactions between the surfactant and the inorganic species. The inorganic species hydrolyzes and condenses into inorganic walls around micelles of a surfactant. After calcinations or solvent extraction to remove surfactants, mesopores thus generate. Surfactants, ionic ${ }^{1,2,3,4}$ or neutral such as primary amine ${ }^{5}$, polyethylene glycol(PEG) ${ }^{6}$, polyvinyl alcohol(PVA) and blockcopolymer P123, F127 $7^{8,9,10}$ have been commonly used as templates for directing the formation of mesopores.

In addition to various types of surfactants, non-surfactant organic compounds can also be used as templates or pore-forming agents, which offer a new way to prepare mesoporous materials, and have characteristics such as various types of organic compounds available, convenient post-treatment and environment friendly ${ }^{11}$. However, there are only a few on the study of nonsurfactant templating route to mesoporous ceria ${ }^{12}$. In this work, we perform synthesis of mesoporous ceria materials in the presence of ceric ammonium nitrate and two organic compounds (glucose and acrylamide). The effect of various synthesis conditions on the properties of mesoporous ceria has been investigated in detail.

\section{EXPERIMENTAL}

\section{Preparation}

Mesoporous ceria were synthesized via hydrothermal method. In a typical experiment, glucose $(0.005 \mathrm{~mol})$, acrylamide $(0.0075 \mathrm{~mol})$ and ceric ammonium nitrate $(0.0025 \mathrm{~mol})$ were dissolved into deionized water $(40 \mathrm{ml})$ one by one with magnetic stirring. Then ammonia solution $(25 \mathrm{wt} \%)$ was added dropwise to the solution until the $\mathrm{pH}$ value was about 10 . After stirring for $5 \mathrm{~h}$, the mixture was transferred into a Teflon-lined autoclave (50 $\mathrm{ml}$ capacity), and the autoclave was sealed and kept at $120-180^{\circ} \mathrm{C}$ for $1-2 \mathrm{~d}$ in an electric oven. Subsequently the autoclave was allowed to cool to room temperature. The solution was filtered and the precipitate was washed with water and alcohol three times. The obtained sample was dried at $80^{\circ} \mathrm{C}$ overnight and calcined at $400^{\circ} \mathrm{C}$ for $4 \mathrm{~h}$ in air.

The samples prepared using glucose (or acrylamide) and ceric ammonium nitrate was denoted by GCeN and ACeN, respectively. And the sample synthesized in presence of glucose, acrylamide and ceric ammonium nitrate was denoted by GACeN.

\section{Characterization}

Powder X-ray diffraction (XRD) data were obtained using an X-ray diffractometer (type D8/ADVNCE made in German) over the range $10^{\circ} \leq$ $2 \theta \leq 90^{\circ}$, at room temperature, operating at $40 \mathrm{kV}$ and $40 \mathrm{~mA}$, using $\mathrm{Cu} \mathrm{K \alpha}$ radiation combined with the nickle filter.

Nitrogen adsorption-desorption isotherms at $77 \mathrm{~K}$ were carried out on an Micrometrics ASAP2020 surface analyzer after degassing of the samples at $150^{\circ} \mathrm{C}$ for $10 \mathrm{~h}$. The surface area was calculated with the BET equation and the pore size distribution was calculated from the desorption branch of the isotherm with the BJH model.

The TEM analyses were performed on a JEM-2010 TEM instrument and the energy of the electrons used was $120 \mathrm{kV}$.

Thermogravimetric analysis (TG) were recorded by DR-4P instrument in air atmosphere with $10 \mathrm{~K} \cdot \mathrm{min}^{-1}$.

\section{RESULTS AND DISCUSSION}

\section{Effect of synthesis conditions}

1.1 Cerium ion valence

In presence of glucose and acrylamide, effect of cerium ion valence on properties of the sample is inspected. As can be seen in Table 1, cerium ion valence is one of the most important variables affecting properties of $\mathrm{CeO}_{2}$. When cerium ion valence is +3 , the surface area of as-prepared sample is very small, and the phase presents hexagonal $\mathrm{CeCO}_{3} \mathrm{OH}$. It has been reported that a complex degradation of glucose takes place in hot alkaline solution, principally resulting in lactic acid, formate, glycolic acid, acetate and carbonate, in which carbonate is product of further decomposition of lactate $\operatorname{etc}^{13,14}$. However as cerium ion valence is +4 , the surface area of as-prepared sample increases significantly and the phase is $\mathrm{Ce}_{2} \mathrm{O}\left(\mathrm{CO}_{3}\right)_{2} \cdot \mathrm{H}_{2} \mathrm{O}$. After calcinations in air at $400^{\circ} \mathrm{C}$ for $4 \mathrm{~h}$, the surface area of the sample decreases from 150 to $122 \mathrm{~m}^{2} \cdot \mathrm{g}^{-1}$. And no matter cerium ion valence, the samples both present cubic fluorite $\mathrm{CeO}_{2}$ after calcinations.

Table 1.- Effect of cerium ion valence on specific surface area and phase of samples"

\begin{tabular}{|c|c|c|c|c|}
\hline \multirow{2}{*}{ Cerium ion valence } & \multicolumn{2}{|c|}{$\begin{array}{c}\text { Specific surface } \\
\text { area }\left(\mathrm{m}^{2} \cdot \mathrm{g}^{-1}\right)\end{array}$} & \multicolumn{2}{c|}{ Phase } \\
\cline { 2 - 4 } & uncalcined & calcined & uncalcined & calcined \\
\hline $\mathrm{Ce}^{3+}$ & 13 & 48 & $\begin{array}{c}\text { Hexagonal } \\
\mathrm{CeCO}_{3} \mathrm{OH}\end{array}$ & $\begin{array}{c}\mathrm{Cubic} \\
\mathrm{CeO}_{2}\end{array}$ \\
\hline $\mathrm{Ce}^{4+}$ & 150 & 122 & $\mathrm{Ce}_{2} \mathrm{O}\left(\mathrm{CO}_{3}\right)_{2} \cdot \mathrm{H}_{2} \mathrm{O}$ & \\
\hline
\end{tabular}

${ }^{*}$ Hydrothermal treatment at $180^{\circ} \mathrm{C}$ for $2 \mathrm{~d}$.

1.2 Composition of raw materials

When cerium ion valence is +4 , the influence of raw materials composition on properties of mesoporous ceria has been investigated. As shown in Table 2, 
when the starting materials are glucose and ceric ammonium nitrate, namely, acrylamide is absent, the surface area of uncalcined GCeN samples is only $11 \mathrm{~m}^{2} \cdot \mathrm{g}^{-1}$. The diffraction peaks at $2 \theta$ of about $17.8,24.6,30.6,43.6,44.2$, $47.4,50.5$ and 54.0 correspond to the (002), (100), (112), (300), (114), (302), (220) and (222) planes of hexagonal-phase $\mathrm{CeCO}_{3} \mathrm{OH}$ (Fig. 1a). As noted above, the decomposition of glucose in hot alkaline solution principally results in carbonate. And ceric ion is easily reduced to cerous ion by glucose or its degradation products. Therefore $\mathrm{CeCO}_{3} \mathrm{OH}$ is produced.

Table 2.- Specific surface area and phase of samples synthesized with different starting compositions

\begin{tabular}{|c|c|c|}
\hline Samples* & $\begin{array}{c}\text { Specific surface } \\
\text { area }\left(\mathrm{m}^{2} \cdot \mathrm{g}^{-1}\right)\end{array}$ & Phase \\
\hline (a)GCeN (uncalcined) & 11 & Hexagonal $\mathrm{CeCO}_{3} \mathrm{OH}$ \\
\hline (b)ACeN(uncalcined) & 73 & $\mathrm{Cubic} \mathrm{CeO}_{2}$ \\
\hline (c)GACeN(uncalcined) & 150 & $\mathrm{Ce}_{2} \mathrm{O}_{\left(\mathrm{CO}_{3}\right)_{2} \cdot \mathrm{H}_{2} \mathrm{O}}$ \\
\hline (d) GACeN(calcined) & 122 & $\mathrm{Cubic} \mathrm{CeO}_{2}$ \\
\hline
\end{tabular}

* Hydrothermal treatment at $180^{\circ} \mathrm{C}$ for $2 \mathrm{~d}$.

When starting with acrylamide and ceric ammonium nitrate in the preparation and absence of glucose, the surface area of uncalcined ACeN sample is $73 \mathrm{~m}^{2} \cdot \mathrm{g}^{-1}$. From Fig. $1 \mathrm{~b}$, the X-ray diffraction peaks at $2 \theta$ of 28.6, $33.2,47.5,56.5,76.7,79.1$ and 88.5 homologize with (111), (200), (220), (311), (331), (420) and (422) planes respectively, which are indexed to cubic fluorite structure for $\mathrm{CeO}_{2}$. It is expected that ceric ammonium nitrate reacting with ammonia solution yields hydrous cerium (IV) hydroxide and then translated into ceria under hydrothermal treatment, in which acrylamide appears to have no effect. When both glucose and acrylamide are used in the synthesis, the uncalcined GACeN products shows the highest surface area of $150 \mathrm{~m}^{2} \cdot \mathrm{g}^{-1}$ and the diffraction peaks are observed with $2 \theta$ of $16.0,20.6,24.1,26.5,30.2$, 38.3 and 43.7, which are from the (011), (110), (021), (012), (102), (131) and (221) planes of $\mathrm{Ce}_{2} \mathrm{O}\left(\mathrm{CO}_{3}\right)_{2} \bullet \mathrm{H}_{2} \mathrm{O}$ (Fig. 1c). The intensities of the diffraction peaks are much weaker than others, which reveal the framework of samples is amorphous to a great extent. After calcinations in air at $400^{\circ} \mathrm{C}$ for $4 \mathrm{~h}$, the surface area of sample is $122 \mathrm{~m}^{2} \cdot \mathrm{g}^{-1}$. And the X-ray diffraction curve shows that sample consists of $\mathrm{CeO}_{2}$ with cubic fluorite structure (Fig. 1d).

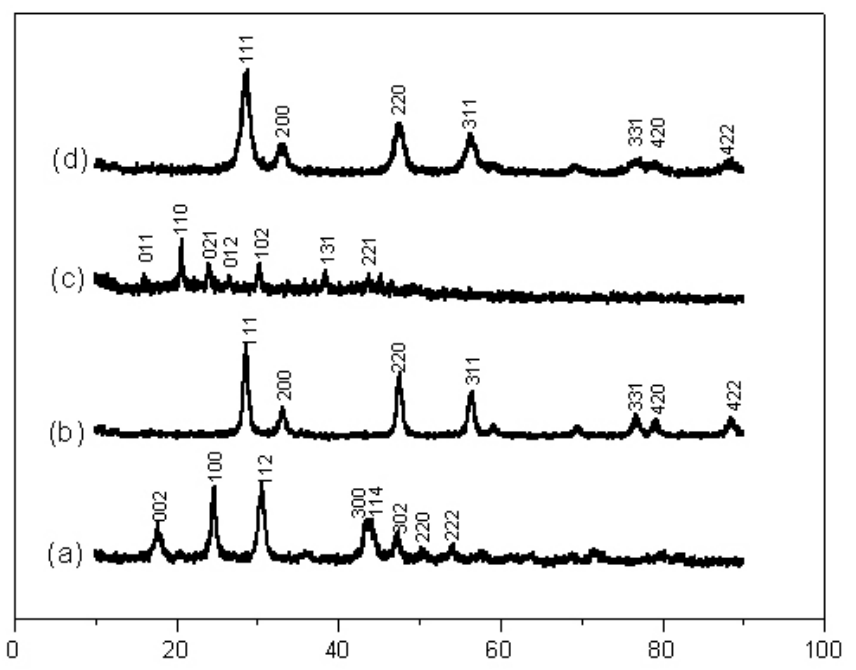

$2 \theta\left(^{\circ}\right)$

Fig. 1 the phases of samples synthesized with different starting compositions: (a) GCeN (uncalcined), (b)ACeN(uncalcined), (c)GACeN(uncalcined) and (d) GACeN(calcined)
1.3 Hydrothermal temperature and reaction time

The effects of hydrothermal temperature and reaction time on surface areas of GACeN samples are presented in Table 3. It can be seen that the increase of hydrothermal temperature results in the decrease of surface areas of uncalcined samples. Especially a rise in temperature from $150 \square$ to $180 \square$ leads to more decrease of surface area. It is probably due to the greater extent of condensation of hydrous cerium hydroxide at higher hydrothermal temperature and thus more shrinkage of pore structure, consequently resulting in lower surface area. But hydrothermal temperature seems to have relatively less effect on the surface areas of calcined samples, since the surface areas of as-prepared samples all decrease to about $120 \mathrm{~m}^{2} \cdot \mathrm{g}^{-1}$ after calcinations, which is likely that the less extent of condensation of framework at lower hydrothermal temperature brings more contraction of framework and more serious collapse of pore structure during calcinations.

Table 3.- Effect of hydrothermal temperature and reaction time on specific surface area of samples.

\begin{tabular}{|c|c|c|c|c|c|c|}
\hline \multirow{2}{*}{$\begin{array}{c}\text { Specific surface } \\
\text { area }\left(\mathrm{m}^{2} \cdot \mathrm{g}^{-1}\right)\end{array}$} & \multicolumn{3}{|c|}{$\begin{array}{c}\text { Hydrothermal temperature } \\
\left({ }^{\circ} \mathrm{C}\right)^{*}\end{array}$} & \multicolumn{4}{|c|}{$\begin{array}{c}\text { Hydrothermal } \\
\text { reaction time }(\mathrm{h})^{*}\end{array}$} \\
\cline { 2 - 7 } & 120 & 150 & 180 & 24 & 48 & 72 \\
\hline uncalcined & 328 & 307 & 165 & 307 & 268 & 193 \\
\hline calcined & 123 & 125 & 117 & 125 & 162 & 112 \\
\hline
\end{tabular}

*Hydrothermal treatment for $1 \mathrm{~d} ;{ }^{*}$ Hydrothermal treatment at $150^{\circ} \mathrm{C}$.

The influence of hydrothermal reaction time on surface areas of GACeN samples is also studied with fixation of hydrothermal temperature at $150^{\circ} \mathrm{C}$. As shown in Table 3 , the surface areas of uncalcined samples decrease with increasing hydrothermal reaction time. The explanation is similar to the above, namely, that the increase of hydrothermal reaction time causes the greater extent of condensation of framework and thus more shrinkage of pore structure and thereby lower surface area. As hydrothermal reaction time increases from 24,48 to $72 \mathrm{~h}$, the surface areas of samples after calcinations shrink $59 \%$, $40 \%$ and $42 \%$ in turn. And with hydrothermal treatment for $48 \mathrm{~h}$, the obtained mesoporous ceria exhibits surface area of $162 \mathrm{~m}^{2} \cdot \mathrm{g}^{-1}$.

\section{Characterizations of samples}

2.1 Nitrogen gas adsorption

$\mathrm{N}_{2}$ absorption-desorption isotherm and pore size distribution of calcined samples is displayed in Fig. 2. As can be seen, the calcined product exhibits type IV isotherm with type H2 hysteresis loop. It indicates that the sample possesses mesoporous structure and ink-bottle-like pores of varying radius ${ }^{15}$ centered in the region $2-10 \mathrm{~nm}$.

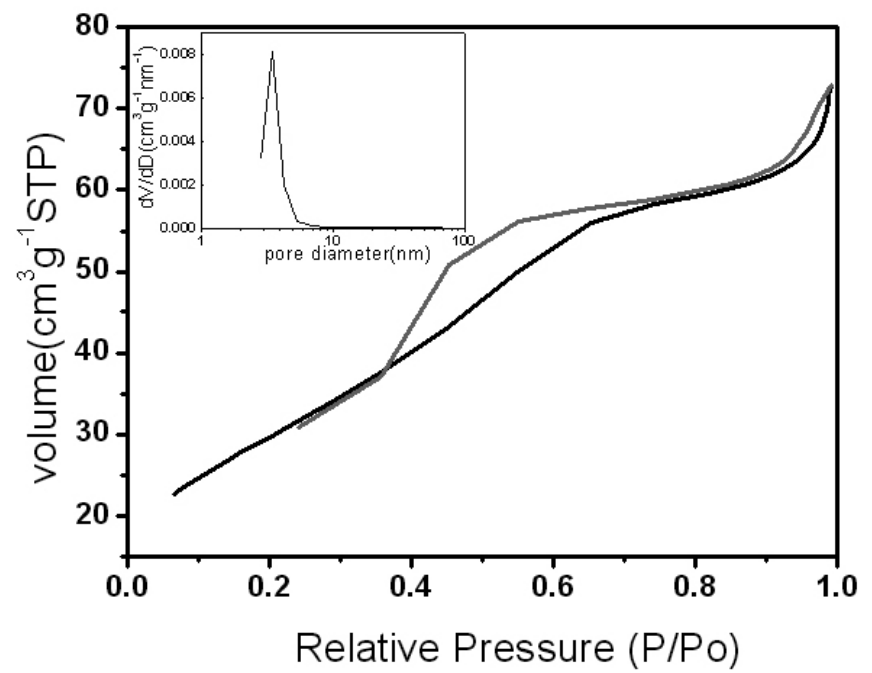

Fig. $2 \mathrm{~N}_{2}$ absorption-desorption isotherm and BJH (Barret-Joyner-Halenda) pore size distribution plot (inset) of calcined samples. 


\subsection{Transmission electron microscopy}

Fig. 3 shows TEM image of mesoporous ceria. It demonstrates crystalline $\mathrm{CeO}_{2}$ aggregates are composed of three-dimensional disordered primary nanoparticles. The average size of the $\mathrm{CeO}_{2}$ nanoparticles is a few nanometers. And the average size of the mesopores between primary nanopaticles is also a few nanometers, which is in accordance with BJH pose size distribution.

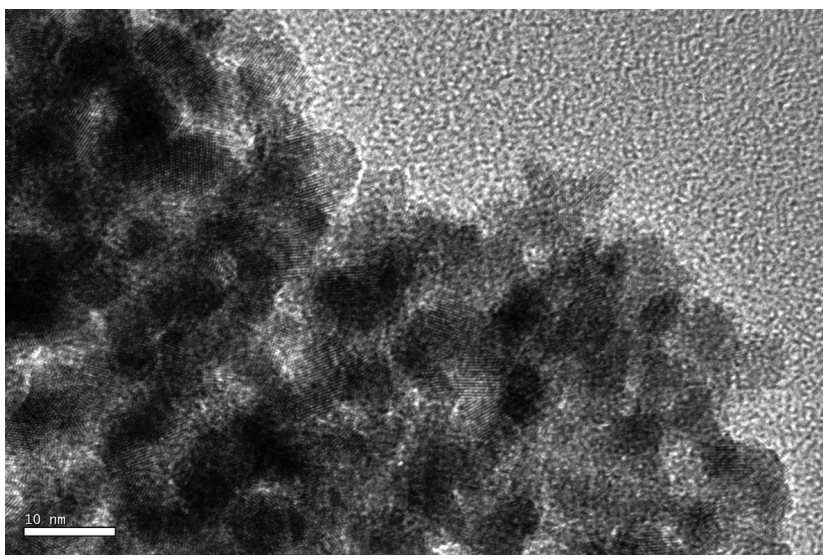

Fig. 3 TEM image of mesoporous ceria (the scale length at the bottom left corner is $10 \mathrm{~nm}$ ).

\subsection{Thermal analysis}

The TG-DTG curve of the as-synthesized sample is shown in Fig. 4. From the DTG curve, it can be seen that there is only a very sharp and narrow peak at $256^{\circ} \mathrm{C}$, which is probably attributed to the thermal decomposition of $\mathrm{Ce}_{2} \mathrm{O}\left(\mathrm{CO}_{3}\right)_{2} \cdot \mathrm{H}_{2} \mathrm{O}$ and the organic substances such as glucose, acrylamide and their ramifications. The complete removal temperature of ionic surfactant template such as SDS and nonionic surfactant template such as F127, PEG are commonly higher than $500^{\circ} \mathrm{C}$. And the removal of surfactant at high temperature easily causes collapse of mesoporous structure and decrease of surface area. Herein non-surfactant organic compounds can be removed at lower temperature, which facilitates to obtain higher surface area.

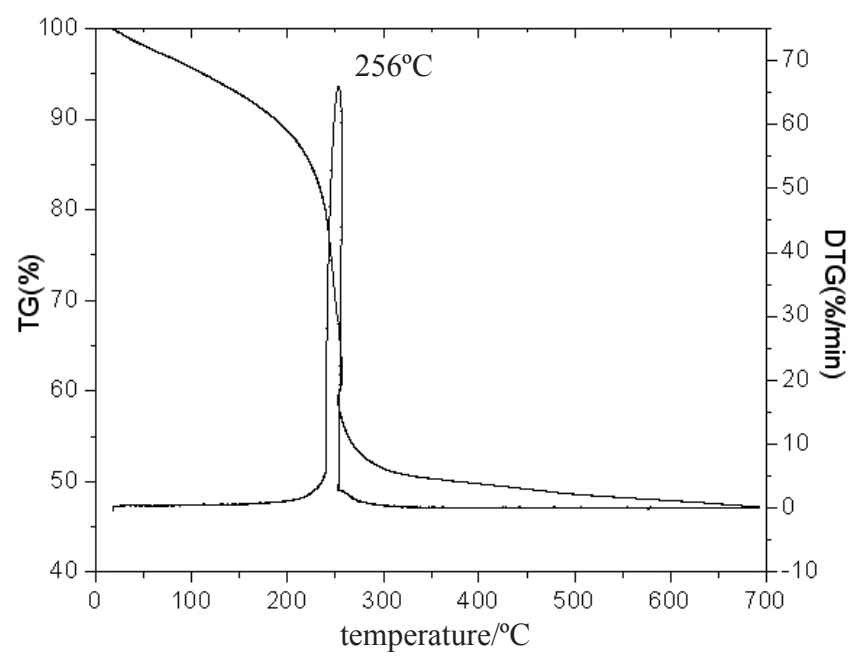

Fig. 4 TG-DTG spectra of uncalcined sample.

\section{Possible mechanism for mesoporous formation}

The above results show that the sample with high surface area can be obtained in the presence of glucose, acrylamide and ceric ion in the synthesis. It has been pointed out that the $\mathrm{Ce}^{4+}$-polyol redox system can initiate acrylamide graft copolymerization onto polyo $1^{16}$. Thus in this study $\mathrm{Ce}^{4+}$ and glucose can form a redox system, which is expected to initiate a graft copolymerization reaction between acrylamide and glucose. The formed branched copolymer molecules containing a $-\mathrm{NH}_{2}$ group are then hydrolyzed and carry positive charges. They can interact with electronegative hydrous cerium hydroxide species via electrostatic Coulomb force or hydrogen bonding and thus act as templates for subsequent self-assembly processes, leading to the formation of mesoporous materials with high surface areas. While $\mathrm{Ce}^{3+}$ is used in the synthesis, it can not form a redox system with glucose, thus can not initiate a graft copolymerization reaction between acrylamide and glucose, ultimately produce product with low surface area.

\section{CONCLUSION}

In this study, we synthesize mesoporous ceria with high surface area using glucose, acrylamide, ceric ammonium nitrate under hydrothermal condition. The primary particle and the mesopore of ceria are both a few nanometers in size. And the results show that using ceric ion instead of cerous ion as cerium source can produce mesoporous $\mathrm{CeO}_{2}$ with higher surface area. Furthermore introducing both glucose and acrylamide in the preparation will cause considerable increase of the surface areas of products. Compared to many surfactants, herein non-surfactants organic compounds glucose and acrylamide can be removed at relative low temperature, beneficial to maintaining mesoporous structure.

\section{ACKNOWLEDGEMENT}

The authors thank the financial support from Specialized Research Fund for the Doctoral Program of Higher Education (Grant No. 20040403011).

\section{REFERENCES}

1.- Zhang, J. H.; Yang, Y. Q.; Shen, J. M. et al. J. Mol. Catal. A: Chem. 237, $182,(2005)$.

2.- Chen, L. F.; Gonzáleza, G.; Wang, J. A. et al. Appl. Surf. Sci. 243, 319, (2005).

3.- Feng, S. S.; Gu, Y. Y.; Li, J. L. et al. Chin. J. Chem. 25, 1499, (2007).

4.- Yada, M.; Kitamura, H.; Ichinose, A. et al. Angew. Chem. Int. Ed. 38, 3506, (1999).

5.- Sinha, A. K.; Suzuki, K. J. Phys. Chem. B. 109, 1708, (2005).

6.- Gu, Y. Y.; Feng, S. S.; Li, J. L.; Gu, X. K. et al. J. Rare Earths. 25, 710, (2007).

7.- Yamamoto, S.; Kakihana, M.; Kato, S. J. Alloys Compd. 297, 81, (2000)

8.- Suzuki, K.; Sinha, A. K. J. Mater. Chem. 17, 2547, (2007).

9.- Corma, A.; Atienzar, P.; García, H. et al. Nature Mater. 3, 394, (2004).

10.- Hung, I. M.; Wang, H. P.; Lai, W. H. et al. Electrochimica Acta. 50, 745, (2004).

11.- Wei, Y.; Jin, D.; Ding, T. Et al. Adv. Mater. 3, 313, (1998).

12.- Yang, R.; Liu, J. H.; Li, M. J. Chin. Rare Earth Soc. (in Chinese) 22, 739, (2004).

13.- Ellis, A. V.; Wilson, M. A. J. Org. Chem. 67, 8469, (2002).

14.- Yang, B. Y.; Montgomery, R. Carbohydr. Res. 280, 27, (1996).

15.- Bumajdad, A.; Zaki, M. I.; Eastoe, J. et al. J. Coll. Interf. Sci. 302, 501, (2006).

16.- Iwakura, Y.; Imai, Y.; Yagi, K. J. Polym. Sci. Part A-1. 6, 801, (1968) 